CARDIOVASCULAR MEDICINE

\title{
Diet in childhood and adult cardiovascular and all cause mortality: the Boyd Orr cohort
}

\author{
A R Ness, M Maynard, S Frankel, G Davey Smith, C Frobisher, S D Leary, P M Emmett, D Gunnell
}

Heart 2005;91:894-898. doi: 10.1136/hrt.2004.043489

See end of article for authors' affiliations

Correspondence to

Dr Andy Ness, Unit of Paediatric and Perinatal Epidemiology, 24 Tyndall Avenue, Bristol BS8 1TQ, UK; andy.ness@bris.ac.uk

10 September 2004

\begin{abstract}
Objective: To examine the association between childhood diet and cardiovascular mortality.
Design: Historical cohort study.

Setting: 16 centres in England and Scotland.

Participants: 4028 people (from 1234 families) who took part in Boyd Orr's survey of family diet and health in Britain between 1937 and 1939 followed up through the National Health Service central register. Exposures studied: Childhood intake of fruit, vegetables, fish, oily fish, total fat, saturated fat, carotene, vitamin $C$, and vitamin $E$ estimated from household dietary intake.

Main outcome measures: Deaths from all causes and deaths attributed to coronary heart disease and stroke.

Results: Higher childhood intake of vegetables was associated with lower risk of stroke. After controlling for age, sex, energy intake, and a range of socioeconomic and other confounders the rate ratio between the highest and lowest quartiles of intake was 0.40 (95\% confidence interval 0.19 to $0.83, p$ for trend $0.01)$. Higher intake of fish was associated with higher risk of stroke. The fully adjusted rate ratio between the highest and lowest quartile of fish intake was 2.01 (95\% confidence interval 1.09 to 3.69 , p for trend 0.01 ). Intake of any of the foods and constituents considered was not associated with coronary mortality. Conclusions: Aspects of childhood diet, but not antioxidant intake, may affect adult cardiovascular risk.
\end{abstract}

\section{C} ardiovascular disease in adulthood is not just a result of classic risk factors (such as blood pressure and smoking $)^{1}$ acting in mid life but also of exposures acting across the lifecourse. ${ }^{2}$ Fatty streaks are present in children. ${ }^{3}$ Furthermore, risk factor levels in childhood predict either the subsequent amount of atheroma found at necropsy or radiographically visible coronary calcification. ${ }^{3}{ }^{4}$ There are, however, limited data on the association between exposures in childhood and cardiovascular mortality. Leg length, an indicator of prepubertal nutritional status, is positively associated with reduced risk of cardiovascular disease in adult life. ${ }^{5}$ Also, adverse childhood socioeconomic circumstances are associated with higher cardiovascular mortality. ${ }^{6}$

Studies suggest that diets low in saturated fat, ${ }^{7}$ high in fruit, vegetables, and fish ${ }^{89}$ and rich in antioxidants ${ }^{10}$ are associated with reduced risk of cardiovascular disease. In the case of antioxidants, despite evidence from laboratory studies $^{11}$ and cohort studies, ${ }^{10}$ trials of supplementation have not reported protective effects. ${ }^{12-14}$ One explanation for the discrepancy between observational studies and trials is that the beneficial effects of antioxidants accrue many years earlier. ${ }^{15}$

We report here on the association between childhood diet and subsequent cardiovascular mortality.

\section{SUBJECTS AND METHODS}

\section{The Boyd Orr cohort}

The methods used in the Carnegie (Boyd Orr) survey of diet and health in pre-second world war Britain have been described previously. ${ }^{5-18}$ In short, 1352 families living in 16 areas of England and Scotland were surveyed between 1937 and 1939. Families were generally identified from deprived districts though some more affluent families were recruited. Around two thirds of families agreed to participate and the majority completed the one week dietary inventory. ${ }^{16}$ The name, age, and address of the children of the families surveyed were used to trace them. Of the 4999 children, aged from 0 to 19 years at the time of survey, 4334 (87\%) had been successfully traced at the time of the analysis. The study team are informed of the death, area of current residence, and emigration of traced cohort members. The cause of death is ascertained from death certificates and classified according to the International classification of diseases, 9th revision (ICD-9).

\section{Data on cohort members}

Occupation of the head of household was recorded as were details of family composition and total family expenditure on food. Social class (a measure of social position based on occupation of head of household) was coded according to the Registrar General's 1931 classification. Household diet was measured in detail. Family food expenditure was measured and weighted by the age and sex of household members according to weightings modified from a 1933 nutritional report. ${ }^{19}$ Household members were weighted according to the estimated cost of their weekly food requirements relative to those of an adult man. Thus, for example, an adult man was given a weighting of 1.00 , an adult woman 0.83 , and a 2 year old 0.54 . Weighted family food expenditure was calculated by dividing total food expenditure by the sum of the weighted values for each family member. No information was available on adult occupation so the subject's Family Health Service Authority (FHSA) area of residence (mean population size about 500 000) when traced or at death was used to allocate an area based Townsend deprivation score to each participant as a measure of adult socioeconomic position. The Townsend score was based on 1991 census data for the FHSA of residence and combined z scores for levels of car ownership, house ownership, overcrowding, and unemployment. ${ }^{20}$

\section{Dietary data}

Dietary data were obtained by means of a seven day household inventory. A weighed inventory of all foods available in the household was recorded in a diary at the beginning of the survey period. A weighed record of all 
subsequent food brought into the home was made and lastly a second inventory was carried out at the end of the survey period. Reanalysis of the food records was necessary to include nutrients not measured in the original study and to make use of advances in analytical techniques. Fruit and vegetable (excluding potato) consumption and intake of vitamin C, vitamin E, carotene, fish, oily fish, fat, and saturated fat were reanalysed according to programmes based on McCance and Widdowson's the composition of foods and supplements. ${ }^{21}$ The database was adapted with pre-war food tables where compositions of 1930s foods were very different or where there was no modern day equivalent. Per capita food and nutrient intake was calculated by dividing daily total intake by the total number of household members regardless of age, sex, or occupation but taking into account meals missed by family members and meals consumed by visitors.

\section{Statistical analysis}

The end points in this analysis are mortality from all causes and deaths attributed to coronary heart disease (ICD-9 codes 410-414) and stroke (ICD-9 codes 430-438). Analyses were carried out in Stata 5.0 (StataCorp LP, College Station, Texas, USA). Poisson regression was used to take account of the longitudinal nature of the data and to allow for reductions in the number at risk over time because of either death or emigration. Rate ratios between quartiles of intake of fruit, vegetables, fish, fat, saturated fat, carotene, vitamin $\mathrm{C}$, and vitamin $\mathrm{E}$ were computed. A test for linear trend was obtained by entering the quartiles as continuous terms. As the sampling unit in this survey was the family, possible clustering effects may arise because cohort members belong to the same families (particularly as the dietary data were collected on families rather than individual subjects). All analyses thus took account of the hierarchical (or clustered) nature of the dataset by using the cluster option in Stata to adjust the rate ratio estimates and the standard errors and thus allow for possible non-independence between study members within a given family. The rate ratios were initially calculated adjusted for age (in five year age groups), sex, and energy intake (as a categorical variable based on quartiles of energy intake). The associations were then calculated with additional adjustment for childhood per capita family food expenditure (as a continuous variable), father's social class, district of residence (as a categorical variable with 16 categories corresponding to the 16 survey centres), period of birth (a categorical variable divided into four categories according to date of birth: born before 1926, born 1926-1930, born 1931-1935, born after 1935), season when family was studied, and Townsend score for current address or place of death. Father's social class was treated as a categorical variable with the following categories: I, II, III (the distinction between manual and non-manual was not introduced until 1951), IV, V, unemployed, and unclassifiable (social class I indicating higher social position and V lower social position). For stroke, where the limited number of stroke deaths precluded fitting such a complex model, the fully adjusted model included age, sex, energy intake, childhood per capita family food expenditure and Townsend score, and father's social class grouped into nonmanual (I and II), manual (III, IV, and V), and other (unemployed and unclassifiable) categories. To explore whether the possible associations between fat intake and cardiovascular mortality may be caused by confounding we repeated these analyses for deaths attributed to smoking related cancers. The presence of associations between dietary fat intake in childhood and smoking related cancers similar to those for cardiovascular disease would suggest the associations were the result of confounding by exposure to tobacco smoke.

\section{Dataset used in the analyses}

This analysis is based on traced cohort members who were resident in Britain on 1 January 1948 and deaths occurring up to 31 July 2000. It is limited to the 4028 subjects for whom complete data were available. The 306 excluded subjects were four subjects with missing dates of birth, 112 who died before the age of 30, nine with no family diet data, 44 with missing family food expenditure, and 137 with missing Townsend score. The numbers of subjects in the analysis are greater than those used in a recent analysis of diet and cancer in this cohort because survival analysis was used and we could therefore include emigrants up to the date of their embarkation. $^{22}$

\section{Ethics}

Ethics committee approval was obtained from local research ethics committees across the UK.

\section{RESULTS}

From the date participants were 30 years old to 1 August 2000, 1010 deaths had been reported among the 4028 cohort members (1995 male and 2033 female subjects from 1234 families) with complete data, after 149525 person-years of follow up (with an average length of follow up of 37 years). Of these 1010 deaths, 298 were attributed to coronary heart disease and 83 were attributed to stroke.

The average age of the children at the time of survey was mean (SD) 7.5 (4.8) years (interquartile range 3.5 to 11.2 years). The mean (SD) energy intake was 9548 (2330) kJ/day (interquartile range 7912 to $10910 \mathrm{~kJ} / \mathrm{day}$ ). Table $\mathrm{l}$ summarises the characteristics of the study population. The results are presented for families rather than individual subjects.

Table 2 shows the mean intake and range of intake of foods and dietary constituents within each quartile of intake (per person per day). The mean difference in intake of foods and dietary constituents across childhood social class groups was compared and for all aspects of diet examined, intakes were greater in the more affluent groups (see table 3 on the Heart website-http://www.heartjnl.com/supplemental).

The age, sex, energy, and family adjusted rate ratios and the fully adjusted rate ratios for all cause mortality were estimated (see table 4 on the Heart website-http:// www.heartjnl.com/supplemental). The rate ratio was lower with higher intake of fruit in childhood but was attenuated after adjustment. The rate ratio between the highest and lowest quartiles of fruit intake was 0.82 (95\% confidence interval (CI) 0.66 to 1.00 , p for trend 0.05 ) after adjustment for age, sex, and energy intake. After further adjustment for childhood family food expenditure, father's social class, district of residence as a child, period of birth, season when studied as a child, and Townsend score for current address or place of death the rate ratio between the highest and lowest quartiles of fruit intake was 0.87 (95\% CI 0.69 to 1.11 , p for trend 0.2 ). There was also a suggestion of a lower rate ratio with higher intake of saturated fat, which appeared more pronounced after full adjustment. The rate ratio between the highest and lowest quartiles of saturated fat intake was 0.91 (95\% CI 0.70 to 1.17, p for trend 0.2) after adjustment for age, sex, and energy intake. After further adjustment for childhood family food expenditure, father's social class, district of residence as a child, period of birth, season when studied as a child, and Townsend score for current address or place of death the rate ratio between the highest and lowest quartiles of intake was 0.83 (95\% CI 0.60 to 1.15 , p for trend 0.1 ). There was no clear association with the other dietary factors examined. 
Table 1 Characteristics of the families* in the Boyd Orr survey of diet and health in pre-second world war Britain (1937 to 1939)

\begin{tabular}{|c|c|}
\hline $\begin{array}{l}\text { Per capita family food expenditure (new } \\
\text { pence/week) }\end{array}$ & 27.7 (21.7 to 37.8$)$ \\
\hline Townsend score $\nmid$ & $-1.6(-2.8$ to 0.9$)$ \\
\hline \multicolumn{2}{|l|}{ Father's social class } \\
\hline I & $19(1.5 \%)$ \\
\hline$\|$ & $89(7.2 \%)$ \\
\hline III & $242(19.6 \%)$ \\
\hline IV & $284(23.0 \%)$ \\
\hline$\vee$ & $176(14.3 \%)$ \\
\hline Unemployed & $323(26.2 \%)$ \\
\hline Unclassifiable & $101(8.2 \%)$ \\
\hline \multicolumn{2}{|l|}{ District of residence as a child } \\
\hline Aberdeen & $24(1.9 \%)$ \\
\hline Barthol Chapel & $31(2.5 \%)$ \\
\hline Barrow & $93(7.5 \%)$ \\
\hline Bethnall Green & $264(21.4 \%)$ \\
\hline Coal Town of Wemyss & $40(3.2 \%)$ \\
\hline Dundee & $91(7.4 \%)$ \\
\hline Edinburgh & $49(4.0 \%)$ \\
\hline Fulham & $82(6.7 \%)$ \\
\hline Hopeman & $24(1.9 \%)$ \\
\hline Kintore & $6(0.5 \%)$ \\
\hline Liverpool & $99(8.0 \%)$ \\
\hline Methlick & $34(2.8 \%)$ \\
\hline Tarves & $100(8.1 \%)$ \\
\hline Wisbech & $145(11.8 \%)$ \\
\hline West Wemyss & $55(4.5 \%)$ \\
\hline Yorkshire & $97(7.9 \%)$ \\
\hline \multicolumn{2}{|l|}{ Period of birth } \\
\hline Before 1926 & $231(18.7 \%)$ \\
\hline $1926-1930$ & $347(28.1 \%)$ \\
\hline $1931-1935$ & $391(31.7 \%)$ \\
\hline After 1935 & $265(21.5 \%)$ \\
\hline \multicolumn{2}{|l|}{ Season when studied as a child } \\
\hline Spring & $470(38.1 \%)$ \\
\hline Summer & $343(27.8 \%)$ \\
\hline Autumn & $209(16.9 \%)$ \\
\hline Winter & $212(17.2 \%)$ \\
\hline
\end{tabular}

Data are median (interquartile range) or number (\%).

*As the individual level data is the same for each family member the data were analysed for the 1234 families that were represented in the main analysis; †Townsend deprivation score based on 1991 census data, calculated as the sum of standardised scores for levels of car ownership, house ownership, overcrowding, and unemployment in the Family Health Service Authority of residence (negative values indicate less deprivation).

The age, sex, energy, and family adjusted rate ratios and the fully adjusted rate ratios for deaths attributed to coronary heart disease were estimated (see table 5 on the Heart website-http://www.heartjnl.com/supplemental). There was a suggestion that the rate ratio was lower with higher total fat intake and that this was more pronounced after adjustment. The rate ratio appeared to be lower in subjects with higher saturated fat intake, particularly after adjustment. Figure 1 shows these results. No association was seen with fruit, vegetables, fish, or intake of antioxidant vitamins.

The age, sex, energy, and family adjusted rate ratios and the fully adjusted rate ratios for deaths attributed to stroke were estimated (see table 6 on the Heart website-http:// www.heartjnl.com/supplemental). The rate ratio was lower with higher intake of vegetables, which was even lower after adjustment. The rate ratio was increased with increased intake of fish. Figure 2 shows these results. There was no association with fruit, fish, fat or antioxidant vitamin intake.

The analyses were repeated with follow up starting from age 50 rather than 30 years. The results were essentially unaltered by the exclusion of the first 20 years of follow up (data not shown).

There were 159 deaths attributed to smoking related cancers including cancer of the mouth and pharynx, oesophagus, pancreas, respiratory tract and urinary tract.
Table 2 Quartiles of each listed food and constituent of childhood diet in the Boyd Orr survey of diet and health in pre-second world war Britain (1937 to 1939)

\begin{tabular}{|c|c|c|c|}
\hline \multicolumn{2}{|c|}{ Quartile of daily dietary intake } & \multirow{2}{*}{$\begin{array}{l}\text { Mean (SD) } \\
0.7(1.4)\end{array}$} & \multirow{2}{*}{$\begin{array}{l}\text { Range } \\
0-4.7\end{array}$} \\
\hline Fruit (g) & 1 (low) & & \\
\hline & $2^{110 v 1}$ & $13.0(4.7)$ & $4.8-21.1$ \\
\hline & 3 & $31.9(6.6)$ & $21.2-45.1$ \\
\hline & 4 (high) & $90.0(53.4)$ & $45.5-556.4$ \\
\hline \multirow[t]{4}{*}{ Vegetables (g) } & 1 (low) & $23.8(10.4)$ & $0-38.8$ \\
\hline & 2 & $47.7(5.7)$ & $38.8-58.1$ \\
\hline & 3 & $68.9(7.1)$ & $58.3-83.1$ \\
\hline & 4 (high) & $116.1(37.6)$ & $83.2-481.2$ \\
\hline \multirow[t]{4}{*}{ Fish (g) } & 1 (low) & $1.8(2.4)$ & $0-6.9$ \\
\hline & 2 & $11.3(2.5)$ & $7.0-15.7$ \\
\hline & 3 & $21.6(3.9)$ & $15.8-29.2$ \\
\hline & 4 (high) & 44.5 (15.5) & $29.2-148.9$ \\
\hline \multirow{4}{*}{ Fat (g) } & 1 (low) & $53.1(7.2)$ & $30.1-63.3$ \\
\hline & 2 & $70.7(4.1)$ & $63.3-77.6$ \\
\hline & 3 & $86.6(5.2)$ & $77.7-96.4$ \\
\hline & 4 (high) & $118.8(20.5)$ & $93.5-229.0$ \\
\hline \multirow[t]{4}{*}{ Saturated fat (g) } & 1 (low) & $19.6(3.2)$ & $8.8-24.0$ \\
\hline & 2 & $27.6(2.3)$ & $24.0-31.4$ \\
\hline & 3 & $35.5(2.6)$ & $31.4-40.4$ \\
\hline & 4 (high) & $52.0(10.8)$ & $40.6-108.9$ \\
\hline \multirow[t]{4}{*}{ Carotene $(\mu \mathrm{g})$} & 1 (low) & $164.8(69.5)$ & $4.5-284.8$ \\
\hline & 2 & $432.6(79.4)$ & $285.1-575.5$ \\
\hline & 3 & 794.3 (141.0) & $576.1-1052.2$ \\
\hline & 4 (high) & $1672.4(779.3)$ & $1053.4-12062.7$ \\
\hline \multirow[t]{4}{*}{ Vitamin C (mg) } & 1 (low) & $14.9(3.7)$ & $5.6-20.4$ \\
\hline & 2 & $24.6(2.4)$ & $20.5-29.1$ \\
\hline & 3 & $34.4(3.2)$ & $29.2-40.3$ \\
\hline & 4 (high) & $58.0(19.6)$ & $40.3-169.4$ \\
\hline \multirow[t]{4}{*}{ Vitamin E (mg) } & 1 (low) & $2.1(0.4)$ & $0.9-2.6$ \\
\hline & 2 & $3.1(0.3)$ & $2.6-3.6$ \\
\hline & 3 & $4.1(0.4)$ & $3.6-4.8$ \\
\hline & 4 (high) & $6.2(1.3)$ & $4.8-17.0$ \\
\hline
\end{tabular}

The age, energy, and sex adjusted rate ratio between the highest and lowest quartiles of total fat intake was 0.89 (95\% CI 0.46 to 1.72 , p for trend 0.80 ). The fully adjusted rate ratio between the highest and lowest quartiles of total fat intake was 0.87 (95\% CI 0.38 to 2.00 , p for trend 0.80 ). The age, energy, and sex adjusted rate ratio between the highest and lowest quartiles of saturated fat intake was 0.70 (95\% CI 0.38 to $1.29, \mathrm{p}$ for trend 0.30 ). The fully adjusted rate ratio between the highest and lowest quartiles of saturated fat intake was 0.62 (95\% CI 0.28 to 1.37 , p for trend 0.30 ).

All cause and cardiovascular mortality was compared between subjects who reported consuming some oily fish $(43 \%)$ and those who reported consuming no oily fish (57\%). There was no association between consumption of oily fish and stroke, coronary, or all cause mortality (data not shown).

\section{DISCUSSION}

We examined the association between childhood diet and cardiovascular and all cause mortality in adulthood. Though we found that higher intake of vegetables in childhood and lower intake of fish in childhood were associated with lower risk of stroke death, the fact that we examined a number of diet-disease associations makes it possible that the associations we have observed are due to chance. There is considerable interest in the effects of childhood diet on adult disease risk but few studies have been able to relate diet in childhood to adult disease experience. We are not aware of any other large epidemiological studies of childhood diet in the late 1930s.

It is possible that the lack of an observed association with other dietary variables in childhood was because a subject's diet in childhood was poorly measured. Usual diet is difficult to measure in free living humans and these measures were based on household rather than individual consumption. 


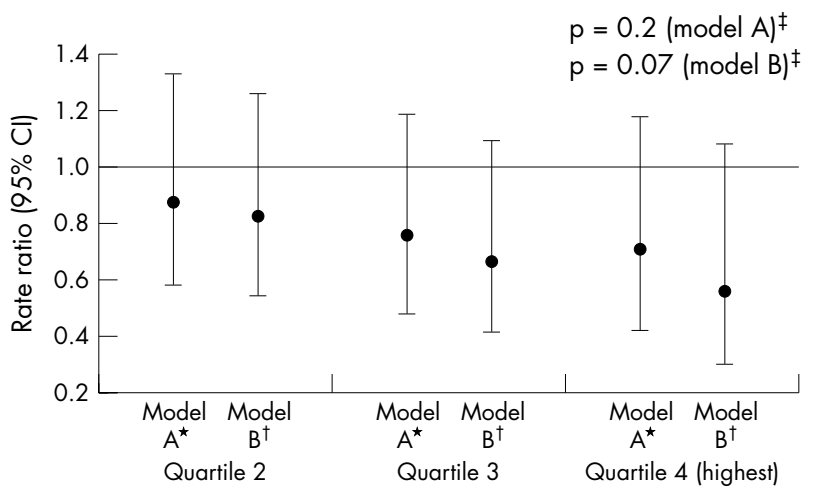

Quartiles of fat intake (versus lowest)

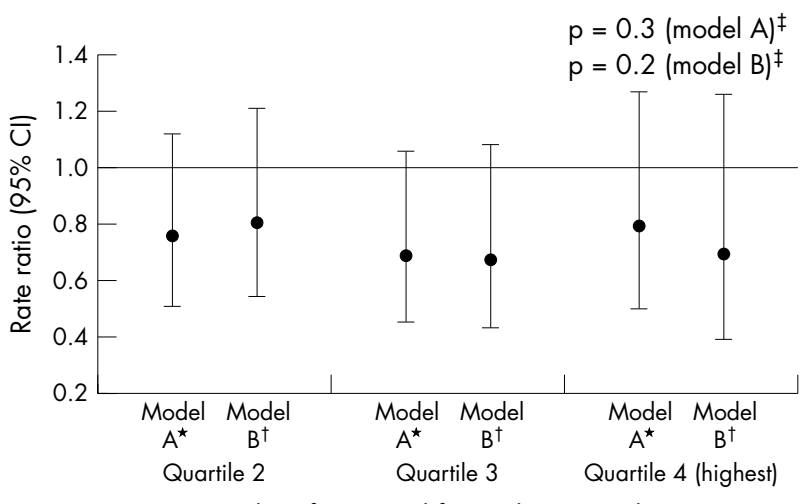

Quartiles of saturated fat intake (versus lowest)

Figure 1 Childhood fat and saturated fat intake and coronary heart disease mortality in the Boyd Orr survey of diet and health in pre-second world war Britain (1937 to 1939). *Adjusted for age, energy, and sex; talso adjusted for childhood family food expenditure, father's social class, district of residence as a child, period of birth, season when studied as a child, and Townsend score for current address or place of death; $\ddagger \mathrm{p}$ value for linear test for trend, obtained by entering the quartiles as continuous terms. All models control for within-family clustering of diet by using the cluster option in Stata. Rate ratio and confidence interval (Cl) were calculated using Poisson regression.

Though the cohort was drawn mainly from social classes III and IV the range of dietary intake was large. It is possible, however, that the range of childhood diets was reduced with rationing during and after the second world war. Even if imprecise measurement of childhood diet does obscure real diet-disease associations it does not explain the associations we did observe.

A previous analysis of dietary data from this cohort showed a relation between increased energy intake in childhood and increased cancer risk in adulthood, a finding consistent with findings from animal studies, giving indirect support for the validity of the dietary measure. ${ }^{17}$ The protective association of antioxidants observed with cardiovascular disease has often been based on single measures of diet in adulthood. ${ }^{10}$ If this observed association reflects a causal association between diet in childhood and adult disease and is a result of an association with dietary patterns continued from childhood, then dietary assessment in childhood should be better able to detect an association.

Bias is an unlikely explanation, as dietary data were recorded in advance of the disease and there have been negligible losses to follow up. Confounding is, however, a possible explanation for some of these findings. Fruit intake and vegetable intake were both highly socially patterned in this cohort.

Adjustment for confounders did not reduce the size of the observed associations. The measures of social position (based

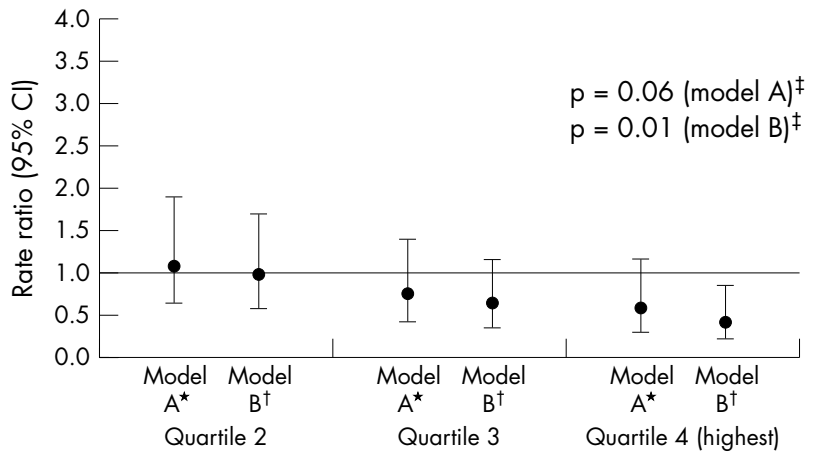

Quartiles of vegetable intake (versus lowest)

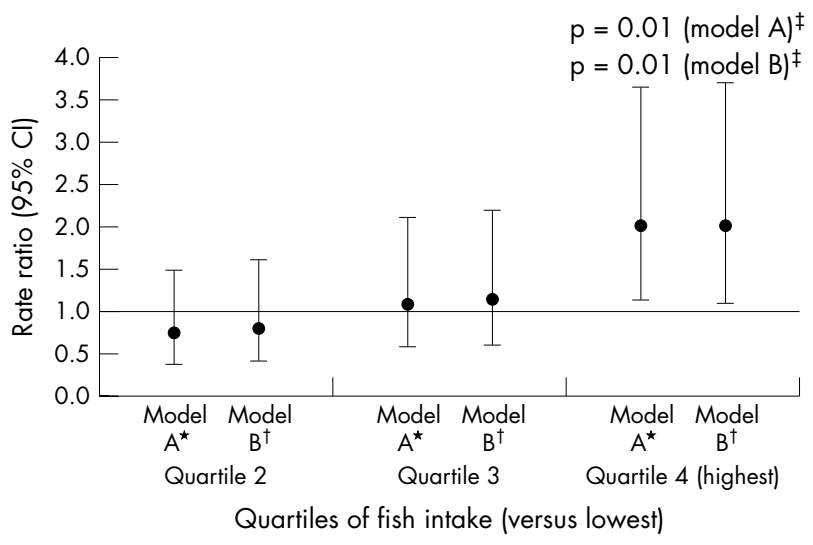

Figure 2 Childhood vegetable and fish intake and stroke mortality in the Boyd Orr survey of diet and health in pre-second world war Britain (1937 to 1939). *Adjusted for age, energy, and sex; †also adjusted for childhood family food expenditure, father's social class, district of residence as a child, period of birth, season when studied as a child, and Townsend score for current address or place of death; $\ddagger p$ value for linear test for trend, obtained by entering the quartiles as continuous terms. All models control for within-family clustering of diet by using the cluster option in Stata. Rate ratio and $\mathrm{Cl}$ were calculated using Poisson regression.

on occupation of the head of household in childhood and area deprivation score in adult life) were imperfect and we have no other data on adult exposures for the whole cohort. The protective association with higher intake of vegetables in childhood and stroke mortality may thus result from residual confounding by social position in childhood or by associated adult vegetable intake, ${ }^{23}$ or by associated adult lifestyle behaviours or material circumstances.

The apparent protective associations of childhood saturated fat intake and childhood total fat intake with all cause mortality and coronary mortality may well result from confounding, as subjects who had higher fat intakes came from a higher social class. Although adjustment for confounders tended to make these associations stronger we did find similar protective associations between total fat (and saturated fat intake) and mortality from smoking related cancers, indicating that the observed relation may be confounded by adult smoking patterns. It is, however, possible that higher fat intake in childhood may have beneficial effects (particularly in those who had lower fat intakes in adult life) if children whose diets were rich in saturated fat were able to adapt to lifelong high intakes. ${ }^{24}$ Also, increased intake of foods rich in saturated fat in the form of milk in childhood may lead to increased growth and thus increased height, which is associated with reduced coronary disease risk. ${ }^{5}$

We are aware of one study that has recently reported on diet in childhood and subsequent coronary heart disease 
morbidity. ${ }^{25}$ In this study based in the UK, 1946 birth cohort diet was measured by a single 24 hour recall at age 4 years in 1950. Fat intake, vegetable intake, and vitamin $\mathrm{E}$ intake were not associated with coronary morbidity by 53 years of age. Fruit intake and in particular vitamin $C$ intake appeared to be protective, though the protective effect of vitamin $\mathrm{C}$ was attenuated after adjustment for socioeconomic factors. ${ }^{25}$

The higher risk of stroke death associated with increased fish intake is unlikely to be due to confounding as fish intake was greater in those of higher social class. A detrimental effect of higher fish intake on stroke risk would fit with temporal trends in fish consumption and stroke in the UK and Japan. ${ }^{26}{ }^{27}$ It is also consistent with the suggestion that fish intake in early life may influence risk of stroke, particularly haemorrhagic stroke through an effect on membrane concentrations of arachidonic acid. ${ }^{28}$

In summary, we found no evidence that increased intake of antioxidants in childhood is protective against death from all causes or from cardiovascular disease. The protective associations we observed between vegetable intake and stroke mortality may result from confounding. These associations along with the adverse association between fish intake and stroke risk require confirmation.

\section{ACKNOWLEDGEMENTS}

Dr Ness and Dr Leary analysed the data. Dr Ness wrote the first draft of the paper. Professor Frankel, Professor Davey Smith, and Dr Gunnell established the cohort. Dr Maynard, Dr Frobisher, and Mrs Emmett coded the dietary data and calculated the nutrient intakes. All the authors helped to prepare the final manuscript for publication. Dr Ness is guarantor for the study. We thank Professor Peter Morgan, Director of the Rowett Research Institute, and Walter Duncan, honorary archivist to the Rowett Research Institute, for allowing us access the original research records and Dr Richard Martin, who helped to provide an updated dataset. We also acknowledge all the research workers and subjects who participated in the original survey in 1937-9. Work on the Boyd Orr cohort has been funded by the World Cancer Research Fund, the Medical Research Council, and the British Heart Foundation.

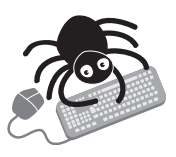

To view tables 3-6 visit the Heart website-http:// www.heartinl.com/supplemental

\section{Authors' affiliations}

A R Ness, C Frobisher, S D Leary, P M Emmett, Unit of Paediatric and Perinatal Epidemiology, University of Bristol, Bristol, UK M Maynard, MRC Social \& Public Health Sciences Unit, Glasgow, UK S Frankel, G D Smith, D Gunnell, Department of Social Medicine, University of Bristol

Sources of support: Work on the Boyd Orr cohort has been funded by the World Cancer Research Fund, the Medical Research Council, and the British Heart Foundation.

\section{REFERENCES}

1 Stamler J. Established major coronary risk factors. In: Marmot $M$, Elliott $P$, eds. Coronary heart disease epidemiology: from aetiology to public health. Oxford: Oxford University Press, 1992:35-66.

2 Kuh D, Ben Shlomo Y. A lifecourse approach to chronic disease epidemiology. Oxford: Oxford University Press, 1997.

3 Berenson GA, Srinivasan SR, Bao W, et al. Association between multiple cardiovascular risk factors and atherosclerosis in children and young adults. N Engl J Med 1998;338:1650-6.

4 Mahoney LT, Burns TL, Stanford W, et al. Coronary risk factors measured in childhood and young adult life are associated with coronary artery calcification in young adults: the Muscatine study. J Am Coll Cardiol 1996;27:277-84

5 Gunnell DJ, Davey Smith G, Frankel S, et al. Childhood leg length and adult mortality: follow up of the Carnegie (Boyd Orr) survey of diet and health in pre-war Britain. J Epidemiol Community Health 1998:52:142-52.

6 Davey Smith G, Hart C, Blane D, et al. Adverse socioeconomic conditions in childhood and cause specific mortality: prospective observational study. BMJ 1998;316:1631-5.

7 Hooper L, Summerbell CD, Higgin JPT, et al. Dietary fat intake and prevention of cardiovascular disease: systematic review. BMJ 2001;322:757-63.

8 Ness AR, Powles JW. Fruit and vegetables and cardiovascular disease: a review. Int J Epidemiol 1997;26:1-13.

9 Hooper L, Ness AR, Higgin JPT, et al. GISSI-Prevenzione trial. Lancet 1999;354:1557.

10 Lonn $E$, Yusuf $S$. Is there a role for antioxidant vitamins in the prevention of cardiovascular disease? An update on epidemiological and clinical trials data. Can J Cardiol 1997; 13:957-65.

11 Witztum JL. The oxidation hypothesis of atherosclerosis. Lancet 1994;344:793-5.

12 Ness AR. Beyond beta-carotene-antioxidants and cardiovascular disease. Int J Epidemiol 2001;30:143-4.

13 Ness AR, Egger M, Davey Smith G. Meta-analysis seems to exclude benefit of vitamin C supplementation. BMJ 1999;319:577.

14 Hooper L, Ness AR, Smith GD. Antioxidant strategy for cardiovascular diseases. Lancet 2001;357:1705.

15 Steinberg D. Clinical trials of antioxidants in atherosclerosis: are we doing the right thing? Lancet 1995;346:36-8

16 Gunnell DJ, Frankel S, Nanchahal K, et al. Lifecourse exposure and later disease: a follow-up study based on a survey of family diet and health in prewar Britain (1937-1939). Public Health 1996;110:85-94.

17 Frankel SJ, Gunnell DJ, Peter TJ, et al. Childhood energy intake and adult cancer: the Boyd Orr cohort study. BMJ 1998;316:499-504.

18 Frankel S, Davey Smith G, Gunnell D. Childhood socioeconomic position and adult cardiovascular mortality: the Boyd Orr cohort. Am J Epidemiol 1999; 150:1081-4

19 British Medical Association. Report of Committee on Nutrition. London: British Medical Association, 1933.

20 Phillimore $\mathrm{P}$, Beattie $A$, Townsend $\mathrm{P}$. Widening inequality of health in northern England, 1981-91. BMJ 1994;308:1125-8.

21 Holland B, Welch AA, Unwin ID, et al. McCance \& Widdowson's the composition of food, 5th ed. London: HMSO, 1991

22 Maynard M, Gunnell D, Emmett $P$, et al. Fruit, vegetables, and antioxidants in childhood and risk of adult cancer: the Boyd Orr cohort. J Epidemiol Community Health 2003;57:218-25.

23 Krebs-Smith SM, Heimendinger J, Patterson BH, et al. Psychosocial factors associated with fruit and vegetable consumption. Am J Health Promot 1995; 10:98-104.

24 Bateson P. Fetal experience and good adult design. Int J Epidemiol $2001 ; 30: 928-34$

25 Wadsworth $M$, Hardy R. Coronary heart disease morbidity by age 53 years in relation to childhood risk factors in the 1946 birth cohort. In:National Heart Forum. A lifecourse approach to coronary heart disease prevention. Scientific and policy review. London: Stationery Office, 2003.

26 Walsh GP. Dietary change and coronary heart disease. Med Hypotheses 1990;31:135-9.

27 Kimura N. Changing patterns of coronary heart disease, stroke, and nutrient intake in Japan. Prev Med 1983;12:222-7.

28 Golfetto I, Min Y, Wang Y, et al. Serum cholesterol and haemorrhagic stroke. Lancet $2001 ; 358: 508$. 